\title{
The Australia-New Zealand connection re-visited, with two new species of Cartomothrips (Thysanoptera, Phlaeothripinae)
}

\author{
LAURENCE A. MOUND ${ }^{1} \&$ ANNETTE K. WALKER ${ }^{2}$ \\ ${ }^{1}$ CSIRO Ecosystem Sciences, GPO Box 1700, Canberra, Australia. E-mail: Laurence.Mound@csiro.au \\ ${ }^{2} 13$ Tahi Street, Mapua, Nelson, 7005, New Zealand
}

\begin{abstract}
The distribution of the six species in Cartomothrips is considered, and a key provided for their identification. $C$. tofti sp.n. is described from New Zealand; manukae is widespread in New Zealand but also found in Tasmania; neboissi is infrequent in New Zealand but common in southern Australia; laughlini is known only from South Australia; browni breeds in the seed capsules of some Eucalyptus species and thus presumably is an Australian species but has also been found in Brazil, California, Kenya and New Zealand; C. abrsi sp.n. is described from Tasmania.
\end{abstract}

Key words: New Zealand, Australia, Thysanoptera, Phlaeothripidae, Myrtaceae, distribution

\section{Introduction}

More than 120 species of the insect order Thysanoptera are recorded from New Zealand, and $25 \%$ of these are recognized as having been introduced from Australia (Mound 2006). This insect order is not an ideal subject for biogeographic studies, because many species are so easily distributed widely around the world, both by winds and by the horticultural trade (Mound 1983). Despite this, relationships between New Zealand and Australia, as evidenced by species of the genus Cartomothrips, were discussed by Mound \& Walker (1982), and the possibility of vicariance across the Tasman in the genus Lomatothrips was considered by Mound (2006). The trans-Tasman distribution of the genus Cartomothrips is difficult to evaluate. Of the six species here recognized in this genus, two are known only from Australia, one is presumably Australian but has been widely distributed around the world in Eucalyptus seed capsules, one is known only from New Zealand, and two are known from both sides of the Tasman. There is no certainty concerning the area of origin of either of these latter two species, C. manukae and $C$. neboissi, but they breed within the dried fruiting capsules of particular species of Myrtaceae in the genera Kunzea and Leptospermum, and these plants are closely related to (or even considered synonymous with) Australian species.

The purpose of this article is to re-examine the four previously described species of Cartomothrips, to described one new species from Tasmania, also one new species that has been found recently on the Dennison Plateau, situated within the Protected Natural Area of the Ngakawau Ecological District (Overmars et al. 1998) in the north-west of South Island, New Zealand. The elevated, geologically distorted, tableland of Buller coal measures rises steeply from the Westport coastal plain. Although lower than most alpine areas in New Zealand (500-1040m), it retains the characteristics of a harsh alpine environment, giving rise to an invertebrate fauna more characteristic of higher altitudes. Mean annual rainfall is over $6000 \mathrm{~mm}$ and a notable climatic feature is fog caused by moist oceanic air ascending the western escarpment. The steep sided fissures that dissect the sandstone pavements on the plateau provide protection, and an accumulation of soil, that encourages diverse plant communities, and it is within one of these fissures at $680 \mathrm{~m}$ that the new species of Cartomothrips was found. 


\section{Abbreviations, depositaries and acknowledgements}

Abbreviations are used for the pronotal setae as follows: am—anteromarginal; aa—anteroangular; ml—midlateral; epim-epimeral (notopleural); pa-posteroangular. Type specimens are deposited in the New Zealand Arthropod Collection (NZAC), Landcare Research, Auckland, and the Australian National Insect Collection (ANIC), CSIRO Ecosystems Sciences, Canberra. Richard Toft of Entecol Ltd., is gratefully acknowledged, by the name tofti, for his fortitude and humour when collecting under the sometimes very difficult circumstances on the Plateau. The species name abrsi is in acknowledgement of support provided by ABRS, Canberra, this species having been collected in Tasmania as part of the Bush Blitz programme. Campbell Robertson, Environmental Manager of Buller Coal generously provided the funds to collect on the Denniston Plateau and his help and that of Bathurst Resources Ltd is acknowledged with gratitude. Rhys Buckingham, Fred Overmars, Richard Nichol and Matt Charteris, part of the Denniston Plateau Ecological Survey team, all provided help and advice and Shannel Courtney of the Department of Conservation helped with botanical detail.

\section{Cartomothrips Stannard}

Cartomothrips Stannard, 1962: 38. Type-species C. browni Stannard.

Described originally for two species, one from Australia (Victoria) and one from New Zealand, two further species were described subsequently from southern Australia (Mound \& Walker 1982). A new identification key to the species in the genus is provided here, because some character states in the previously published key (Mound \& Walker 1982) have proved difficult to interpret when examining more recent and larger samples. In contrast, the chaetotaxy of tergite IX of males, and the form of the pore plate on sternite VIII of males, seem to provide reliable species distinctions. Throughout most of the family Phlaeothripidae, the chaetotaxy of tergite IX is remarkably stable, with three pairs of major setae (referred to as S1, S2 and S3), and a small intermediate seta between both S1/ S2 and S2/S3 (Fig. 15). Males of Phlaeothripinae usually have setae S2 short and stout, and in the males of three Cartomothrips species these setae are exceptionally small, 20-30 microns long and actually shorter than the pairs of intermediate setae. In contrast, in the males of the New Zealand species described below setae S2 are about 50 microns long, more than half the length of S1, and in the sixth species, C. manukae, setae S2 are as elongate as those of females and equally as long and slender as S1 and S3.

Systematic relationships of the genus remain enigmatic. Stannard suggested that it was related to Teuchothrips, but species of that genus have only a single sensorium on antennal segment III, as in all of the leaf-feeding members of the Liothrips-lineage (Mound \& Marullo 1996). In contrast, Cartomothrips species have usually been found within the dry seed capsules of particular Myrtaceae species, where they are presumed to feed on fungal hyphae. Moreover, they all have three sensoria on antennal segment III and, with the exception of one new species described below, they all have three sensoria on antennal segment IV. This antennal sensoria formula is more typical of the fungus-feeding species in the Phlaeothrips- lineage (Mound \& Marullo 1996). Cartomothrips is probably derived from Hoplothrips, a worldwide genus with species on dead branches, and a generic definition is provided by Mound \& Walker $(1982,1984)$.

\section{Key to species}

1. Tergite IX internally with male genital complex visible (Fig. 6); sternite VIII with transverse pore plate of varying shapes (Figs

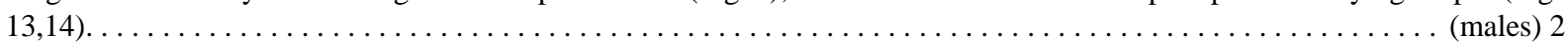

- . $\quad$ Tergite IX internally with longitudinal fustis visible (Fig. 5); pore plate not developed on sternite VIII . .........(females) 7

2. Antennal segments III-V yellow at base (Fig. 4); fore wing sub-basal seta S3 much shorter than setae S1 and S2 . abrsi sp.n. Antennal segments IV-V uniformly dark brown (Fig. 2), III brown but sometimes slightly paler at extreme base; fore wing

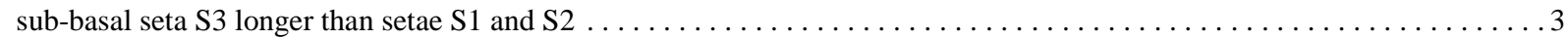

3. Tergite IX setal pair S2 less than 25 microns long, shorter than the intermediate setae between $\mathrm{S} 1$ and $\mathrm{S} 2$, and about 0.5 as long

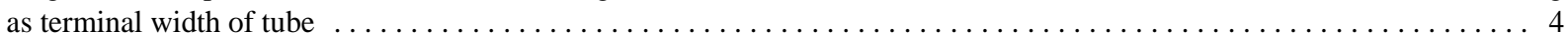
Tergite IX setal pair S2 at least 40 microns long, longer than the intermediate setae between S1 and S2, and longer than

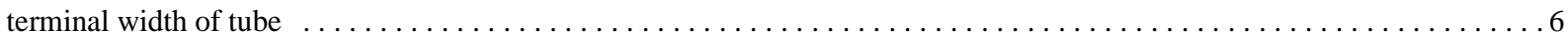

4. Tergite IX setal pair S1 about as long as basal width of tube, apices weakly capitate $\ldots \ldots \ldots \ldots \ldots \ldots$. . . . . . . . . . 


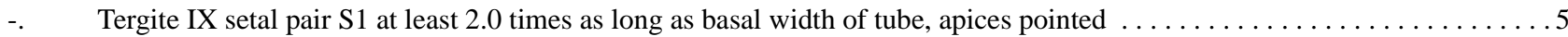

5. Sensoria on antennal segment III \& IV exceptionally broad at base, length about 2.5 times the basal width; anterior margin of

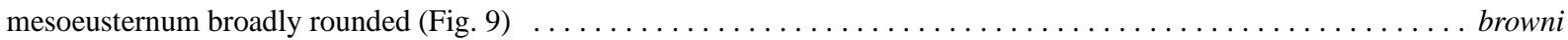
Sensoria on antennal segments III \& IV slender, length at leaset 3.0 times the basal width; anterior margin of mesoeusternum

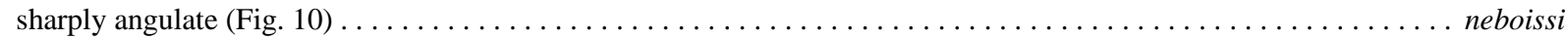

6. Antennal segment IV with 3 sensoria; tergite IX setae S1, S2 \& S3 all equally long, about as long as tube; pore plate extending

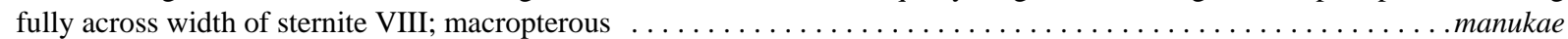
Antennal segment IV with 4 sensoria; tergite IX setae S1 \& S3 about 0.6 as long as tube, S2 about 0.35 as long as tube; pore plate on sternite VIII small and transverse (Fig. 13); micropterous . . . . . . . . . . . . . . . . . . tofti sp.n.

7. Posteroangular setae on tergites VI \& VII about 2.0 times as long as median length of these tergites; tergite IX setae S1 about

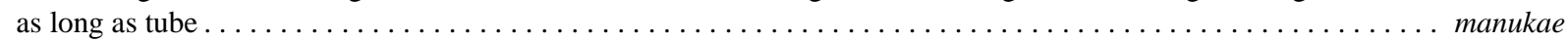
Posteroangular setae on tergites VI \& VII less than 1.5 times as long as median length of these tergites; tergite IX setae S1 less

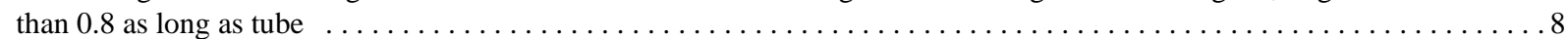

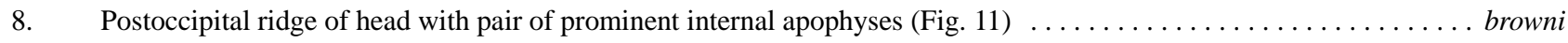

-. $\quad$ Postoccipital ridge of head with paired internal apophyses weak or absent $($ Figs 4,12$) \ldots \ldots \ldots \ldots \ldots \ldots$

9. Postocular setae longer than dorsal length of eye, arising close to eye (Fig. 2); antennal segment IV with 4 sensoria;

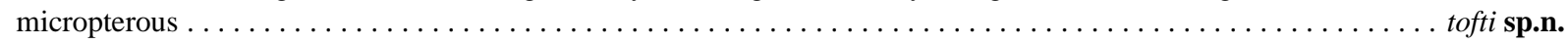
Postocular setae shorter than dorsal length of eye, arising well behind eye (Fig. 4); antennal segment IV with 3 sensoria;

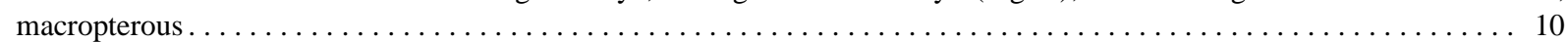

10. Antennal segments III-V yellow at base; fore wing sub-basal seta $\mathrm{S} 3$ shorter than $\mathrm{S} 1$ and $\mathrm{S} 2 \ldots \ldots \ldots$. $\ldots \ldots$. $\ldots$ sp.n. Antennal segments IV-V uniformly dark brown, III brown but sometimes slightly paler at extreme base; fore wing sub-basal

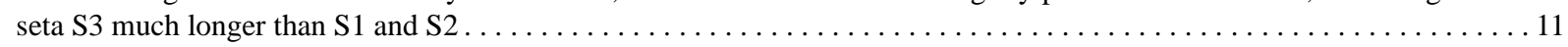

11. Tergite IX setae S1 weakly capitate, length less than 0.5 of tube; tergites VI \& VII posteroangular setae shorter than median

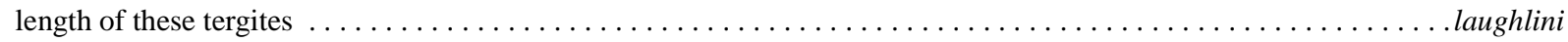
Tergite IX setae S1 finely pointed, length more than 0.5 of tube; tergites VI \& VII posteroangular setae slightly longer than median length of these tergites $\ldots \ldots \ldots \ldots \ldots \ldots \ldots \ldots \ldots \ldots \ldots \ldots \ldots \ldots \ldots \ldots \ldots \ldots \ldots \ldots \ldots \ldots \ldots \ldots \ldots \ldots \ldots \ldots$

\section{Cartomothrips abrsi sp.n.}

(Figs 3, 4, 7, 12, 14)

Female macroptera. Body and legs brown, fore tarsi paler, tube darkest; antennae dark brown but III yellow in basal third, IV yellow in basal quarter, V with pedicel yellow; major setae all pale.

Head longer than wide, cheeks weakly convex, with few weak setae; postocular setae apically blunt, not extending to posterior margin of eyes (Fig. 4); postoccipital ridge without internal apophyses; maxillary stylets close together medially, retracted to eyes. Antennae 8-segmented, III and IV each with 3 stout sensoria; VIII broad at base. Pronotum transverse, with weak sculpture lines (Fig. 4); notopleural sutures complete; anteromarginal setae minute, midlateral and posteroangular setae small and acute, anteroangular and epimeral setae bluntly pointed. Mesonotum transversely reticulate, lateral setae minute; metanotum reticulate, median setal pair acute (Fig. 3). Fore tarsus with prominent tooth. Fore wing parallel sided, with about 12 duplicated cilia; sub-basal setae S3 minute. Prosternal basantra not developed, ferna small and widely separated (Fig. 7); mesopraesternum reduced to two lateral triangles. Pelta triangular with pair of campaniform sensilla (Fig. 3); tergites II-VII each with 2 pairs of wing-retaining setae, on each tergite the posterior pair larger than anterior pair; major lateral setae blunt to weakly capitate, on IX softly pointed and shorter than tube.

Measurements (holotype female in microns). Body length 2250. Head, length 225; width across cheeks 205; maxillary stylets median separation 15. Pronotum, length 130; width 280; major setae-am 5, aa 25, ml 15, epim 40, pa 25. Metanotal median setae 45. Fore wing length 900. Tergite inner and outer lateral setae (S1, S2), on VII 70, 100; on IX 80, 95. Tube length 150; anal setae 200. Antennal segments III-VIII length 70, 60, 60, 50, 45, 35.

Male macroptera. Closely similar to female in colour and structure, except: postoccipital ridge with pair of weak internal apophyses (Fig. 12); fore tarsal tooth large and broadly based; tergite IX S2 setae short; sternite VIII almost fully occupied by pore plate (Fig. 14).

Measurements (paratype male in microns with small male in parentheses). Body length 2050 (1850). Head length 230 (210). Tergite IX setae S1 115 (112), S2 28 (33). Tube length 150 (145).

Specimens examined. Holotype female, Australia, Tasmania, 17 Mile Plain, 20km west of Smithton, from Eucalyptus nuts, 11.iii.2010 (Alice Wells), in ANIC, Canberra.

Paratypes: 5 female 5 male taken with holotype.

Comments. A few damaged specimens that are closely similar in structure to abrsi have been studied from Melaleuca quinquenervia in northern New South Wales (Yamba) and Queensland (Townsville). These specimens 
differ from the type series in having the setae on tergite IX rather shorter and with broader apices. They share most of the other character states with the type series, including the colour of the antennae and the very short setae S3 in the sub-basal series of the fore wing.
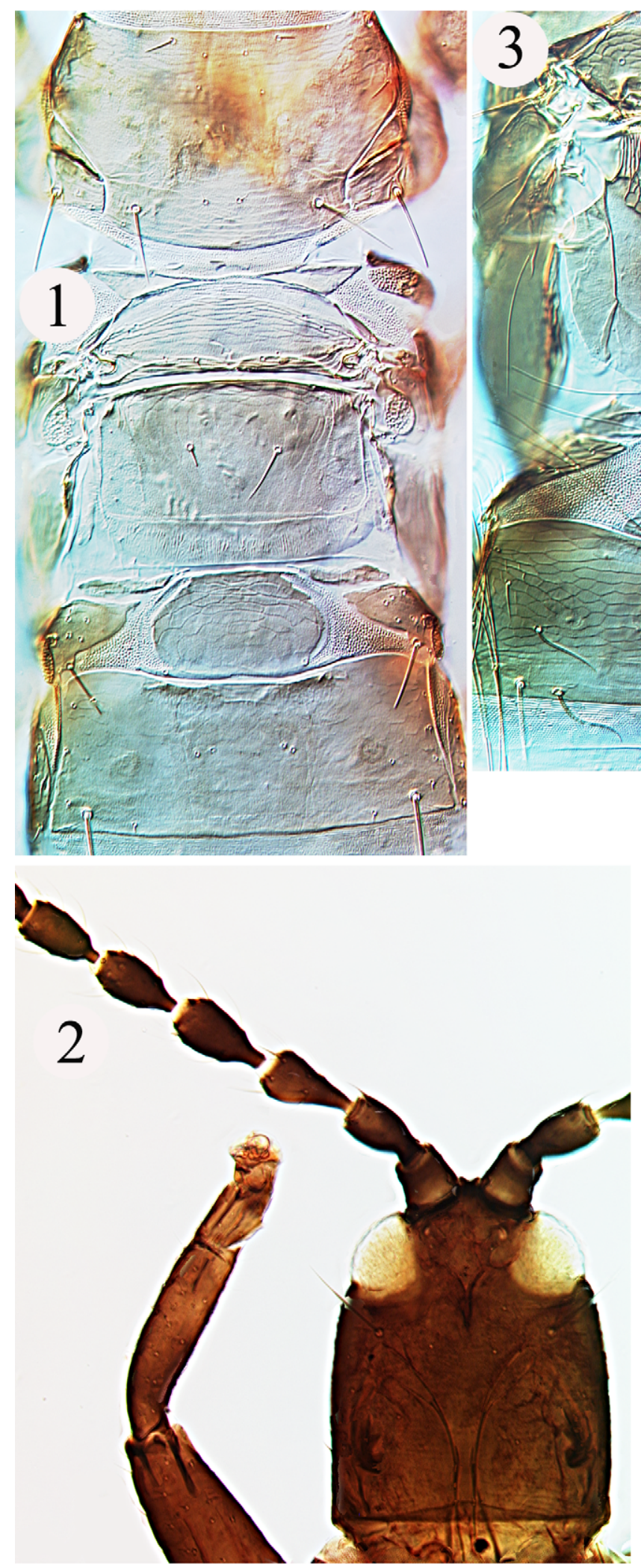
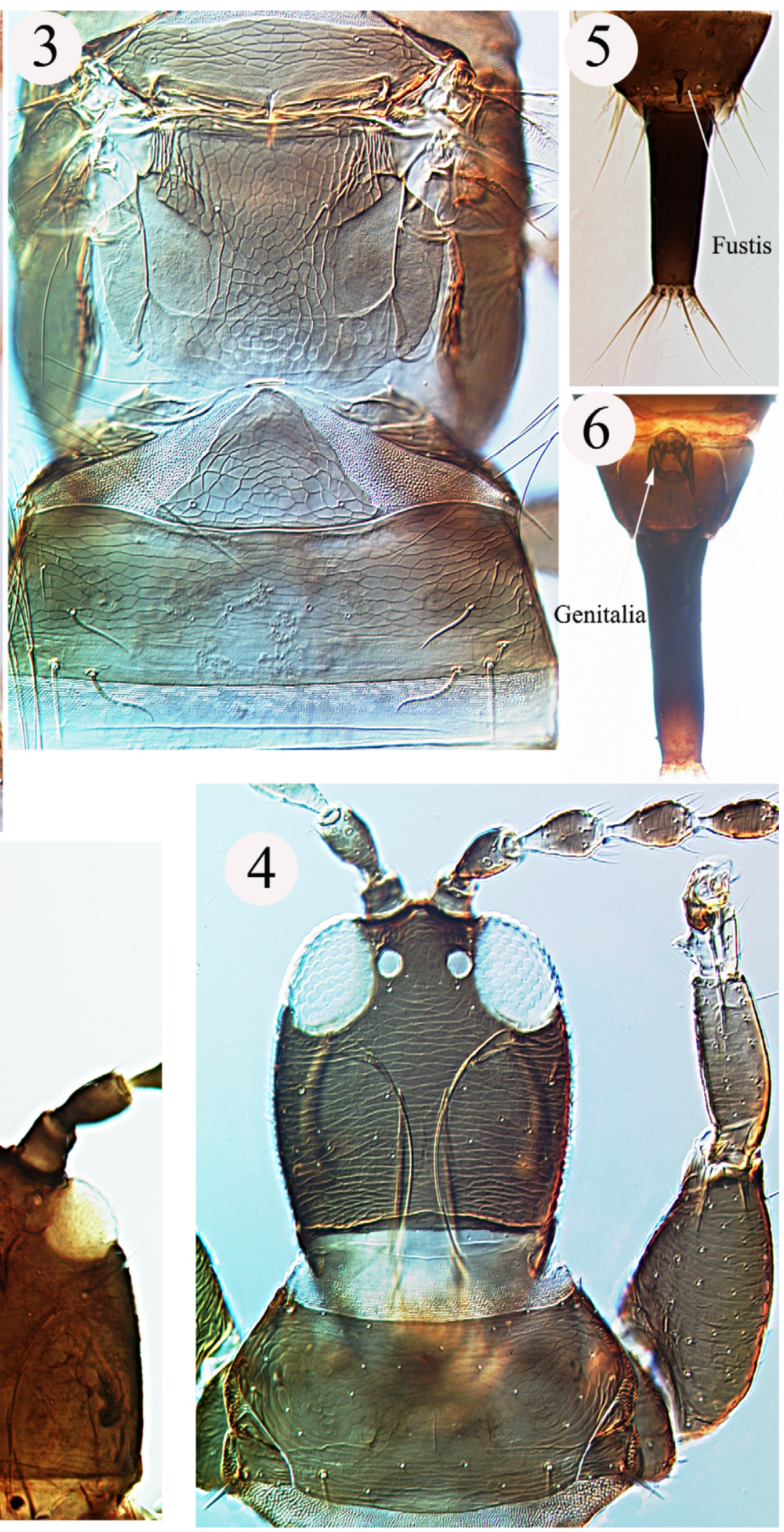

FIGURES 1-5. Cartomothrips species. (1) tofti, pro, meso \& metanota, pelta and tergite II. (2) tofti, head of holotype. (3) $a b r s i$, meso \& metanota, pelta and tergite II. (4) abrsi, head \& pronotum. (5) tofti, female with fustis internally on segment IX. (6) neboissi, male with genital complex internally on segment IX. 

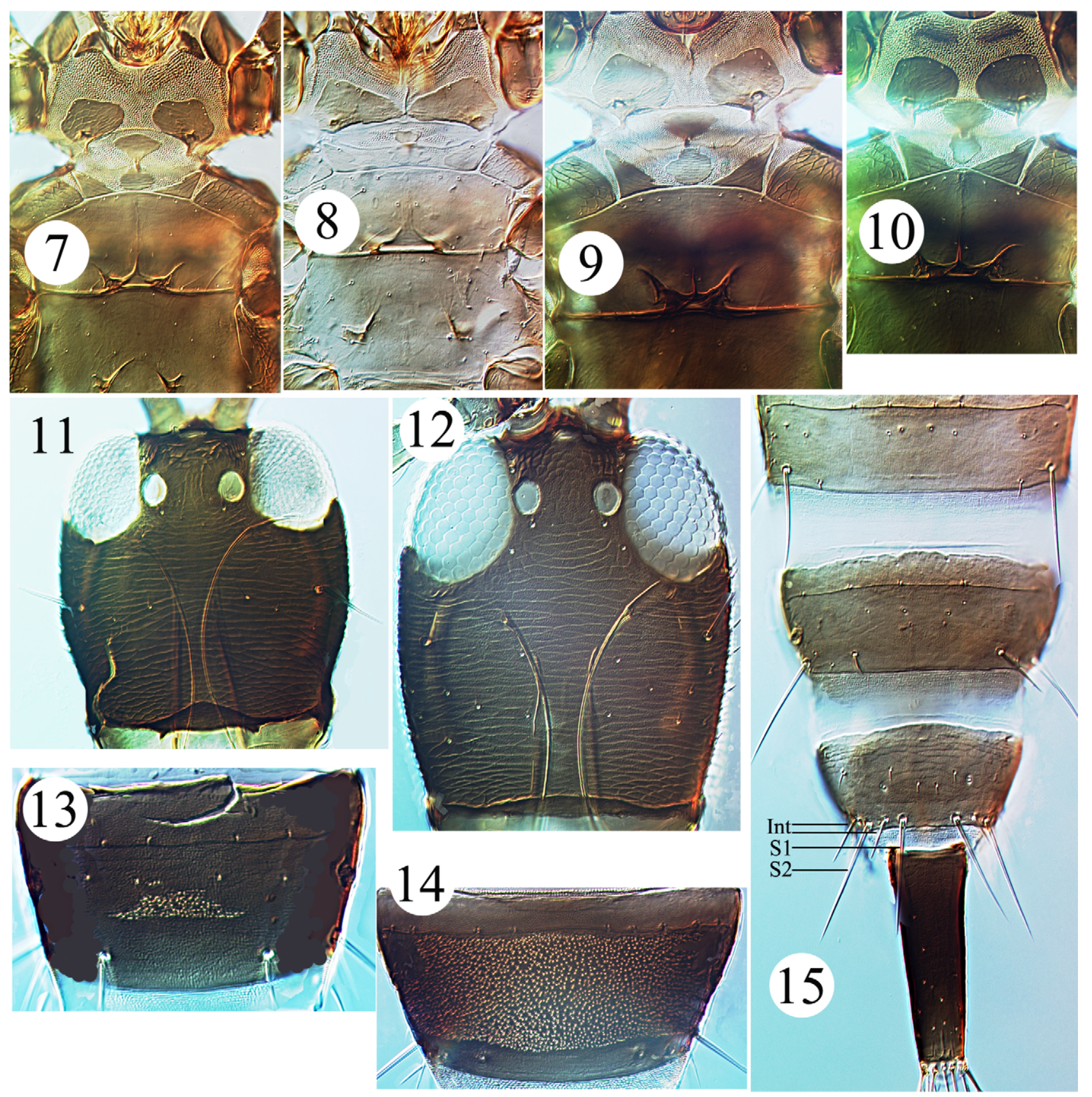

FIGURES 7-15. Cartomothrips species. Thoracic sternites 7-10: (7) abrsi; (8) tofti; (9) browni; (10) neboissi. (11) browni, head showing postoccipital apophyses. (12) abrsi, male head with weak occipital apophyses. Male sternite VIII with pore plate 13-14: (13) tofti; (14) abrsi. (15) tofti, tergites VII-IX and tube of female [S1 \& S2-major setae (S3 arises ventro-laterally); Int-intermediate setae].

\section{Cartomothrips browni Stannard, 1962}

(Figs 9, 11)

Described originally from three females taken in southern Victoria, the only other Australian specimens studied are a series from near Narrogin in Western Australia, taken by insecticide canopy fogging, and a single female from Mt Glorious, near Brisbane, Queensland. In contrast, populations of this species have been found living within the seed capsules of Eucalyptus grandis (and possibly other species of that genus) at the following localities: Riverside, California, U.S.A.; Lincoln, New Zealand; Sao Paulo, southern Brazil; Mt Kilimanjaro, Kenya. 
Presumably the thrips has been distributed around the world by forestry industries through the extensive trade in Eucalyptus seeds. This species is particularly large-bodied, and as in females of the other large species of the genus, manukae, there are two prominent apophyses internally on the postoccipital ridge of the head (Fig. 11). The size of these apophyses is clearly related to body size, they are scarcely developed in males. Despite this postoccipital ridge, browni is probably most closely related to the smaller species, neboissi. In both of them, setae S2 on tergite IX of males are exceptionally short, only half as long as the intermediate pairs of setae that are placed between $\mathrm{S} 1$ and $\mathrm{S} 2$, and between $\mathrm{S} 2$ and $\mathrm{S} 3$.

\section{Cartomothrips laughlini Mound \& Walker, 1982}

This species remains known only from a few specimens beaten from Morgania glabra (Scrophulariaceae) in South Australia, although there is no evidence that this is the plant on which the insect breeds. The males have setae S2 on tergite IX as short as those of browni and neboissi, but both pairs of intermediate setae in laughlini are also short, only a little longer than setae S2. In general structure this species is similar to abrsi, but that is distinguished in both sexes by the bicoloured antennal segments, and the unusually short third seta in the sub-basal series of the fore wing.

\section{Cartomothrips manukae Stannard, 1962}

This species was described as a New Zealand species, where it is recorded widely across both North and South Islands (Mound \& Walker 1986) in association with Leptospermum scoparium, Kunzea ericoides and Metrosideros perforata. In Australia, it has been taken in large numbers in the seed capsules of $L$. scoparium (also L. nitida) in both northwest and southern Tasmania, but only a single female has been studied from the Australian mainland, taken in the Adelaide Hills, South Australia. The lateral setae on the abdomen are longer than in any other species of the genus, and setae S2 on tergite IX of males are exceptionally long.

\section{Cartomothrips neboissi Mound \& Walker, 1982}

(Figs 6, 10)

This species is common in south-eastern Australia, and has been taken infrequently in New Zealand, but only in North Island. It has been found breeding only within the seed capsules of the common myrtaceous shrub, Kunzea ericoides that is sometimes referred to both as Leptospermum ericoides and as Baeckea phylicoides. Adults however have been taken in low numbers from various other plants (Mound \& Walker 1986), suggesting that these adults are dispersive in their behavior.

\section{Cartomothrips tofti sp.n.}

(Figs 1, 2, 5, 8, 13, 15)

Female microptera. Body and legs brown, tube darkest; antennae dark brown with extreme base of III yellow (Fig. 2); major setae weakly shaded. Head longer than wide, cheeks weakly convex, slightly constricted behind eyes, with few weak setae; ocelli small; postocular setae finely pointed, longer than dorsal length of eyes; postoccipital ridge without internal apophyses; maxillary stylets close together medially, retracted to base of postocular setae. Antennae 8-segmented, III with 3 slender sensoria, IV with 4; VIII constricted at base to small collar. Pronotum transverse, with weak sculpture lines (Fig. 1); notopleural sutures complete; anteromarginal setae small, remaining major setae bluntly pointed. Mesonotum transversely reticulate; metanotum without sculpture, one pair of prominent setae medially (Fig. 1). Fore tarsus with small tooth. Fore wing lobe very small. Prosternal basantra not developed; ferna transverse and almost meeting in mid-line (Fig. 8); mesopraesternum reduced to two lateral triangles (Fig. 8). Pelta irregularly D-shaped (Fig. 1), sometimes with very small basal wings; tergal wing-retaining setae small and straight, major setae long and finely pointed, on IX shorter than tube (Fig. 15). 
Measurements (holotype female in microns). Body length 1900. Head, length 225; width across cheeks 185; maxillary stylets median separation 10 . Pronotum, length 125 ; width 250 ; major setae-am 12 , aa 40 , $\mathrm{ml} 25$, epim 70, pa 50. Metanotal median setae 30. Fore wing lobe 60. Tergite inner and outer lateral setae (S1, S2), on III 90, 25; on VII 100, 90; on IX 100, 100. Tube length 160; anal setae 120. Antennal segments III-VIII length 63, 63, 55, $55,54,30$.

Male microptera. Closely similar to female in colour and structure, except: postoccipital ridge with pair of weak internal apophyses; fore tarsal tooth larger with lower margin swollen; tergite IX S2 setae shorter and stouter; sternite VIII with small transverse pore plate (Fig. 13).

Measurements (paratype male in microns). Body length 1550. Head length 210. Tergite IX setae S1 85, S2 50. Tube length 150 .

Specimens examined. Holotype female, New Zealand, South Island, NN, Denniston Plateau, from base of Gahnia procera, 16.iv.2012 (RJ Toft \& AK Walker), in NZAC.

Paratypes, 5 females, 2 males taken with holotype, in NZAC and ANIC, Canberra.

Comments. This new species differs from the other members of the genus in having four, instead of three, sensoria on the fourth antennal segment, and the pore plate on the eighth sternite of males is much smaller (Fig. 13). The curiously dark brown colour of the antennae is shared with the other members of Cartomothrips, but the systematic position of the species requires further study based on field observations and molecular data.

\section{Discussion}

The new species from New Zealand is known only from a single locality, and from this single sample of micropterous adults it is not possible to be certain either of its host associations or its systematics relationships. One species from South Australia, C. laughlini, is also known only from a single sample, taken from dead leaves of a species of Scrophulariaceae. The other four members of the genus have all been found within the dry fruiting capsules of Myrtaceae, and this may eventually be found to be true of the first two. One species, C. browni, has been distributed around the world presumably by the commercial trade in Eucalyptus seeds and seed capsules. The record from Brazil is based on specimens taken in the grounds of the Museu do Eucalipto, near Sao Paulo, whose displays record the introduction to that State of more than 100 species of Eucalyptus for forestry trials. In contrast, C. neboissi appears to be dispersive in its biology, and is probably wind dispersed from south-eastern Australia into New Zealand. Finally, C. manukae differs from the other members of the genus, not only in the far longer setae on the abdomen of both sexes, but also in being abundant widely across New Zealand although common in Australia only in Tasmania. Molecular evidence is needed to consider the possibility that this is sister-species to the rest of the genus, as suggested in Mound \& Walker (1982).

\section{References}

Mound, L.A. (1983) Natural and disrupted patterns of geographical distribution in Thysanoptera (Insecta). Journal of Biogeography, 10, 119-133.

Mound, L.A. (2006) Vicariance or dispersal—trans-Tasman faunal relationships among Thysanoptera (Insecta), with a second species of Lomatothrips from Podocarpus. Papers and Proceedings of the Royal Society of Tasmania, 140, 11-15.

Mound, L.A. \& Marullo, R. (1996) The Thrips of Central and South America: An Introduction. Memoirs on Entomology, International, 6, 1-488.

Mound, L.A. \& Walker, A.K. (1982) Faunal relationships between Australia and New Zealand as indicated by Cartomothrips species (Thysanoptera: Phlaeothripidae). Journal of Natural History, 16, 305-313.

Mound, L.A. \& Walker, A.K. (1986) Tubulifera (Insecta: Thysanoptera). Fauna of New Zealand, 10, 1-140.

Overmars, F.B., Kilvington, M.J., Gibson, R.S., Newell, C.L. \& Rhodes, T.J. (1998) Ngakawau Ecological District. Survey Report for the Protected Natural Areas Programme. New Zealand Protected Natural Areas Programme Survey Report No. 11. $1-178$.

Stannard, L.J. (1962) Cartomothrips, a new genus based on two species from the Australian region (Thysanoptera: Phlaeothripidae). Transactions of the Royal entomological Society of London, 31, 38-40. 